\title{
Potential Risk Assessment of Selected Polycyclic Aromatic Hydrocarbons in Vegetables Grown in Polluted and Non-polluted Areas of Sindh, Pakistan
}

\author{
Raja Karim Bux ${ }^{1}$, Bindia Junejo ${ }^{1}$, Amber Rehana Solangi ${ }^{1}$ and \\ Syed Iqleem Haider Taqvi ${ }^{2 *}$ \\ ${ }^{1}$ National Centre of Excellence in Analytical Chemistry, University of Sindh, Jamshoro, 76080-Pakistan. \\ ${ }^{2}$ Government College and Postgraduate Centre, Hyderabad, Sindh 71000-Pakistan. \\ *Corresponding Author Email: driqleem@gmail.com \\ Received 01 October 2018, Revised 04 November 2018, Accepted 07 November 2018
}

\begin{abstract}
Polycyclic Aromatic Hydrocarbons (PAHs) were determined in vegetables grown in Sindh, Pakistan. The vegetables were collected from both local markets and industrial areas where vegetation was carried out. All three types of vegetables, root vegetables, leafy vegetables and fruit vegetables were selected for analysis. The PAHs were extracted by Soxhlet extraction method and analysed by gas chromatography. The results showed that average concentration of PAHs in vegetables was ranged from $1.62 \pm 0.01 \mu \mathrm{g} / \mathrm{kg}$ to $144.52 \pm 2.51 \mu \mathrm{g} / \mathrm{kg}$. From seven PAHs analyzed, the fluorene was found to be present in almost all vegetable samples and was highest in bitter guard that is $144.52 \pm 2.51 \mu \mathrm{g} / \mathrm{kg}$. Like fluorene, naphthalene and anthracene were also present in all the vegetables but their concentration was not very high $(6.89 \pm 0.03 \mu \mathrm{g} / \mathrm{kg}$ for naphthalene and 2.18 \pm 0.01 for anthracene). Higher concentration of PAHs was observed in samples collected from industrial areas due to the fact that industrial smoke could easily be absorbed by the vegetables grown in those areas.
\end{abstract}

Keywords: PAHs, Vegetables, Gas chromatography, Industries.

\section{Introduction}

The polycyclic aromatic hydrocarbons (PAHs) are a group of organic compounds containing two or more fused benzene rings which are generally generated from the incomplete combustion of petroleum, coal, fuel oil, garbage and other materials. The contamination by PAHs is basically from pathogenic sources [1]. These are persistent group of organic compounds [2]. They can originate from anthropogenic sources as well as from natural processes and have received increasing scientific interest in the recent past. Natural sources generally include bituminous coals, plant debris, forest fires and postdepositional transformation of biogenic precursors. On the other hand, anthropogenic sources mainly result from incomplete combustion of fossil fuels, waste incineration, vehicular traffic, petroleum leakage [3]. Traffic and coal combustion have been considered to be the two most important sources of PAHs in many areas. Therefore, PAHs can serve as geochemical markers for assessing anthropogenic influences within a specific environmental medium because they are closely related to human activities such as anthropogenic combustion processes [4].

The contamination by PAHs varies in different areas according to their molecular weight [5]. Low molecular weight PAHs continued to remain in the gaseous phase can travel long distances in the atmosphere. Due to their longrange atmospheric transport, they can reach and 
affect remote ecosystems at high latitudes and altitudes [6 - 8]. High molecular weight PAHs are assumed to be precursors of the macro aromatic structure of soot. Due to co-emission, as well as the high sorption capacities of elemental carbon for PAHs, it has been suggested that the distribution of PAHs in the soil or sediments is related to the distributions of elemental carbon [9, $10]$.

The PAHs are chemically stable organic compounds and they are very poorly degraded by hydrolysis. The half-lives of PAHs in soil range from months to years. Studies suggested that PAHs and their derivatives are omnipresent in the environment and are found in water, air, soil and foods [11]. The PAHs are listed as priority pollutants by the United States environmental protection agency (USEPA) and European community (EU) and can cause severe diseases like cancer, mutation and reproductive effects [12 - 15]. The PAHs have been investigated by various international organization and concluded that there is clear evidence of mutagenicity/genotoxicity in somatic cells in experimental animals [16, 17]. On the other hand, the PAHs which are not defined as carcinogens may act as synergists [18]. The World Health Organization (WHO) has identified indoor air pollution with $\mathrm{PAHs}$ resulting from the use of solid fuels such as coal and biomass (wood, animal dung and crops) [19].

The occurrence of PAHs in aquatic environments such as rivers or water streams is also of particular importance due to their direct (through consumption of contaminated water) and/or indirect (e.g. through consumption of fish) exposure to humans [20]. PAHs may also present in all types of vegetables like cabbage, turnip, potato etc. which are commonly consumed by the common people. A work has been reported in Punjab, where eight priority PAHs contents have been examined in different varieties of vegetables in Pakistan [20]. The study showed that total PAHs contents were higher for root vegetables like potato and carrot $(13 \mu \mathrm{g} / \mathrm{kg})$ and relatively lower for turnip $(10.9 \mu \mathrm{g} / \mathrm{kg})$ respectively while in fruit vegetables, all peels were found to be more contaminated than cores. Among all, anthracene was higher in all vegetables. Seventy percentages of individuals are exposed to PAHs predominantly from dietary sources [21].

The aim of the present work was to study the levels of selected PAHs in vegetables from both industrial and non-industrial areas of Sindh, Pakistan.

\section{Material and Methods Area of study}

The Sindh is the second most populated province of Pakistan. The city of Hyderabad and Jamshoro are situated at both the left and right banks of river Indus. Hyderabad is the fifth most populated city of Pakistan and second of the Sindh. The agriculture land of Hyderabad and Jamshoro produce variety of vegetables in different seasons throughout the year. The two cities also have industrial areas and power plants.

\section{Sampling and sampling areas}

Initially those vegetables were collected which are close to their season. After that, samples collected periodically from targeted areas. A complete plan of sampling was prepared keeping in mind the potential of PAHs pollution in different location. The samples were collected in polyethene bags and stored in refrigerator in laboratory. Sampling areas were divided into three categories; local market, near power generation plant at Sandoz Road Jamshoro and Latifabad agriculture field.

In Jamshoro, the area from where samples were collected is the Sandoz road Jamshoro near power generation house. The smoke coming out from Jamshoro power plant can be absorbed by the vegetables being grown in the close vicinity. These vegetables are being distributed in local markets without any treatment. Another area of sampling selected was the agriculture land of Latifabad, Hyderabad because domestic wastewater is being used there for the cultivation of vegetables. 


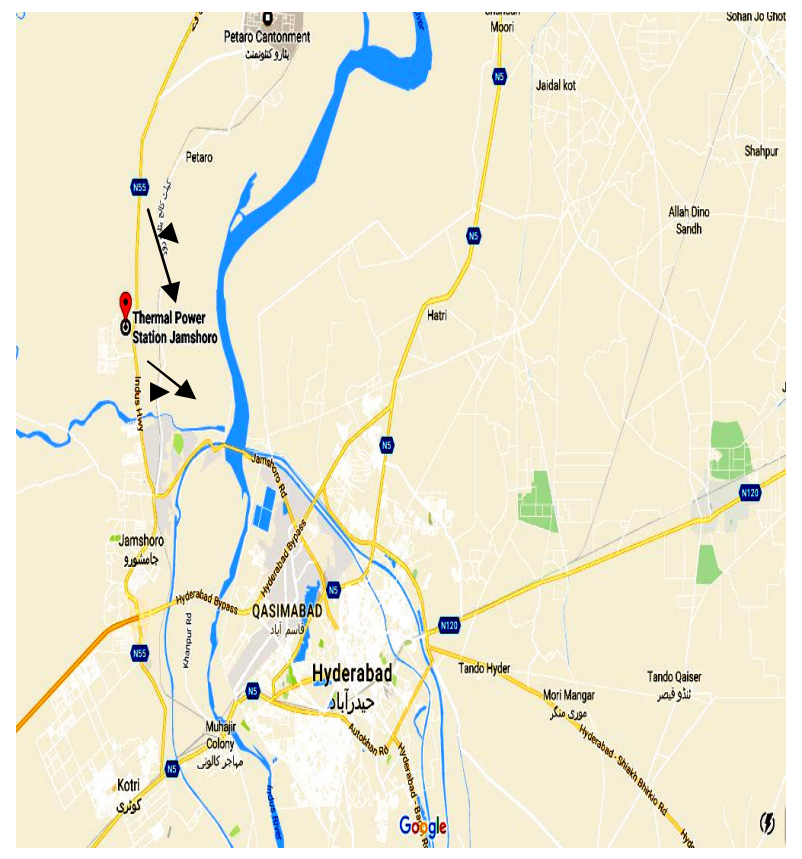

Figure 1. A view of the google map of sampling sites of vegetables collected

\section{Identification and potential risk of PAHs}

In Hyderabad and Jamshoro Districts of Sindh, there are areas where PAHs risk assessment need to be examined. For this purpose a complete survey of the targeted sites were carried out and a comprehensive sampling plan was designed. The areas around Jamshoro Power plant and agriculture land in Latifabad, Hyderabad, Sindh, Pakistan were selected as potentially loaded site for PAHs. Another sampling location is the main local market where vegetable comes from comparatively less polluted areas of the interior of Sindh province. The potential risk of PAHs from Power plant is the smoke carrying PAHs and the location in Latifabad where the use of industrial and sewage waste water for the agriculture purpose.

\section{Chemicals and reagents}

A certified PAH reference material, containing the 7 EPA priority PAHs including; Naphthalene (Np), Anthracene (An), Chrysene (Chry) and Acenaphthylene (Ace) fluorine (F), Benzo $(\alpha)$ Pyrene, $(\mathrm{B}[\alpha]$ Py Fluoranthene (Fi) with 97 to $100 \%$ purity was obtained from Accustandard (New Haven, USA). All the chemicals and reagents i.e., cyclohexane, acetone, anhydrous sodium sulphate, dichloromethane, silica and standards of polyaromatic hydrocarbons obtained from E-Merck. USA).

\section{Extraction apparatus}

Mortar pestle, Soxhlet extractor of quick fit with $500 \mathrm{~mL}$ round bottom flask, burettes, 250 $\mathrm{mL}$ beakers, funnels, $10 \mathrm{~mL}$ airtight tubes for storing samples in refrigerator, fuming hood, oven for drying silica gel were used.

\section{Equipment}

GC-MS analysis was performed on Agilent technologies 6890N Network gas chromatograph coupled to Agilent technologies 5975 Network and HP 5MS with split less injector and a programmable oven coupled with mass detector. The following conditions were used: injection time $1 \mathrm{~min}$, carrier gas helium, flow rate $1 \mathrm{~mL} / \mathrm{min}$, the initial column temperature was $70{ }^{\circ} \mathrm{C}$ for $2 \mathrm{~min}$, while the final temperature was $290{ }^{\circ} \mathrm{C}$ for $10 \mathrm{~min}$. Helium was used as a carrier gas with a split ratio of 50:1, injection temperature was $250{ }^{\circ} \mathrm{C}$ and injection volume was $1 \mu \mathrm{L}$, NPD was used as the front detector while FID was used as the back detector.

\section{Sample preparation}

The samples were washed with fresh running water to remove dust from the surface then with de-ionized water. After washing, the samples were dried and homogenized in mortar pestle. The peels and cores of the samples like potato, bitter gourd, cucumber, eggplant, carrot and turnip were separated manually. After homogenizing, $50 \mathrm{~g}$ of sample was weighed and mixed with $75 \mathrm{~g}$ of preheated anhydrous sodium sulphate so that moisture is removed, then wrapped in filter paper and placed in Soxhlet for the extraction. A mixture of cyclohexane and acetone in 2:1 ratio was used a solvent for the extraction of PAHs, the extraction was carried out for eight hours [20, 22].

Extract was purified by column chromatography with silica as stationary phase. After passing the extract from the column, $75 \mathrm{~mL}$ of dichloromethane was passed as eluent, which 
take out PAHs from the column. The eluent was pre-concentrated up to $2 \mathrm{~mL}$ and analyzed using GC-MS. All the samples were taken in triplicate and results mentioned are in average and all error observed was less than $5 \%$.

\section{Results and Discussion}

The goal of this study was to analyze vegetable samples purchased from local markets as well as from potentially polluted areas. Samples collected from industrial areas contained larger concentration of PAHs because smoke coming out of industries directly absorbed by vegetables which were being grown in that area and were sold in local markets.

All the standards were prepared in dichloromethane as solvents because these were easily soluble in this solvent at room temperature and all the vegetable samples were also prepared in same solvent.

\section{Calibration of PAHs}

Calibrations of all the standards were carried out using dichloromethane as the solvent. Different concentrations i.e. $5 \mathrm{ppm}, 10 \mathrm{ppm}, 15$ ppm, $20 \mathrm{ppm}$ and $25 \mathrm{ppm}$ were prepared for the calibration. All of the regression assumptions tested in linearity were verified for the plots. All the calibration plots were found to have regression around $\mathrm{r}=0.99$. The samples were tested in their triplicate and the average results are tabulated in the discussion.

\section{Quantification of PAHs}

Table 1 shows the concentration of seven PAHs in seven different vegetables commonly consumed by people. It can be observed that in majority of samples, peels are more contaminated than cores because of easy exposure to PAHs. It can also be observed from the Table 1 that fluorine contains exceptionally higher concentration than other PAHs and was commonly present in all samples. Naphthalene, anthracene, chrysene and acenaphthylene were also found commonly in all the samples.
Table 2 shows the concentration of PAHs in vegetables which were analyzed in total. The results shows tha acenaphthylene was not observed in tomato. Chrysene was not observed in okra, spinach and cabbage. Unlike these fluoranthene and $\mathrm{B}$ (a) $\mathrm{P}$ are rarely found in samples.

Table 3 contain the results of the vegetable collected from Sandoz road located in the vicinity of the Jamshoro power plant. Vegetables were tested for their peel and core. Results suggest that, fluorene, acenaphthylene, naphthalene and anthracene contain sufficient amount of these PAHs in peel as well as in core of three vegetables found in this agricultural land. Chrysene and Benzo(a)Pyrene is only found in peel and core of cucumber where as fluoranthene is only present in core of cucumber

The results of samples collected from Sandoz road near Jamshoro power plant are shown in Table 4. Three samples were tested for the seven PAHs and almost all samples caries small amount of PAHs except chrysene and fluoranthene which is absent in coriander. Other vegetables contain appreciable amount of fluorine.

Table 5 and 6 contain results of the vegetable samples collected from cultivated area of Latifabad, Hyderabad. These vegetables were grown using wastewater of the area and some of the industrial effluent also include in it. The cucumber, beets and eggplant were analyzed for their peel and core separately (Table 5) while coriander, oaks, spinach and tomato were tested as whole vegetable. Table 5 shows that chrysene is only present in the core of cucumber and beet, $\mathrm{B}(\mathrm{a}) \mathrm{P}$ only in cucumber whereas fluoranthene and naphthalene not detected in cucumber. The three PAHs fluorine, acenaphthylene and anthracene are found in peel and core of three vegetables samples. Table 6 shows that chrysene and $\mathrm{B}(\mathrm{a}) \mathrm{P}$ not found in coriander oaks and spinach. The fluoranthene not found in tomato, acenaphthylene not found in coriander and naphthalene not found in spinach. Whereas, fluorine and anthracene found in all four vegetables tested as whole. The concentration of fluorine is found to be highest in all vegetable samples. It is a general trend that fluorine is present in high amount in almost all vegetable samples tested in this studies. 
Table 1. Concentration of vegetables in $\mu \mathrm{g} / \mathrm{kg}$ collected from Jamshoro local market.

\begin{tabular}{|c|c|c|c|c|c|c|c|c|}
\hline Vegetable & Parts & Chrysene & Fluoranthene & Fluorene & $\mathbf{B}(\mathbf{a}) \mathbf{P}$ & Acenaphthylene & Naphthalene & Anthracene \\
\hline \multirow[t]{2}{*}{ Bittergourd } & Core & $5.06 \pm 0.09$ & $3.78 \pm 0.05$ & $28.51 \pm 0.83$ & $5.13 \pm 0.12$ & $1.33 \pm 0.03$ & $5.87 \pm 0.13$ & $2.05 \pm 0.04$ \\
\hline & Peel & $\mathrm{Nd}$ & $3.79 \pm 0.08$ & $260.54 \pm 4.2$ & $5.31 \pm 0.08$ & $6.45 \pm 0.09$ & $7.06 \pm 0.08$ & $2.16 \pm 0.03$ \\
\hline \multirow[t]{2}{*}{ Cucumber } & Core & $1.76 \pm 0.03$ & $\mathrm{Nd}$ & $56.17 \pm 0.91$ & $5.13 \pm 0.08$ & $3.82 \pm 0.06$ & $6.53 \pm 0.12$ & $2.07 \pm 0.05$ \\
\hline & Peel & $9.57 \pm 0.10$ & $\mathrm{Nd}$ & $64.09 \pm 2.2$ & $\mathrm{Nd}$ & $6.07 \pm 0.08$ & $5.88 \pm 0.07$ & $2.01 \pm 0.01$ \\
\hline \multirow[t]{2}{*}{ Turnip } & Core & $6.51 \pm 0.13$ & $\mathrm{Nd}$ & $53.19 \pm 0.83$ & $\mathrm{Nd}$ & $4.69 \pm 0.06$ & $5.75 \pm 0.09$ & $2.14 \pm 0.05$ \\
\hline & Peel & $\mathrm{Nd}$ & $3.78 \pm 0.08$ & $68.50 \pm 2.2$ & $\mathrm{Nd}$ & $5.96 \pm 0.08$ & $6.29 \pm 0.07$ & $2.08 \pm 0.01$ \\
\hline \multirow[t]{2}{*}{ Potato } & Core & $1.23 \pm 0.02$ & $\mathrm{Nd}$ & $68.57 \pm 1.63$ & $\mathrm{Nd}$ & $3.63 \pm 0.05$ & $5.64 \pm 0.08$ & $2.02 \pm 0.04$ \\
\hline & Peel & $2.02 \pm 0.01$ & $4.81 \pm 0.04$ & $79.04 \pm 2.4$ & $\mathrm{Nd}$ & $4.81 \pm 0.05$ & $5.71 \pm 0.07$ & $2.19 \pm 0.02$ \\
\hline \multirow[t]{2}{*}{ Carrot } & Core & $6.91 \pm 0.08$ & $\mathrm{Nd}$ & $30.11 \pm 0.87$ & $5.12 \pm 0.07$ & $\mathrm{Nd}$ & $5.62 \pm 0.04$ & $2.06 \pm 0.05$ \\
\hline & Peel & $39.23 \pm 0.53$ & $\mathrm{Nd}$ & $40.34 \pm 0.8$ & $\mathrm{Nd}$ & $6.59 \pm 0.08$ & $5.68 \pm 0.06$ & $2.02 \pm 0.03$ \\
\hline \multirow[t]{2}{*}{ Eggplant } & Core & $1.70 \pm 0.02$ & $\mathrm{Nd}$ & $40.20 \pm 1.20$ & $\mathrm{Nd}$ & $3.65 \pm 0.04$ & $6.43 \pm 0.07$ & $1.98 \pm 0.06$ \\
\hline & Peel & $6.70 \pm 0.09$ & $\mathrm{Nd}$ & $84.68 \pm 2.5$ & $\mathrm{Nd}$ & $6.04 \pm 0.07$ & $5.99 \pm 0.06$ & $1.98 \pm 0.01$ \\
\hline
\end{tabular}

Table 2. Concentration of PAHs in vegetables samples in $\mu \mathrm{g} / \mathrm{kg}$ totally analyzed, collected from local market Jamshoro.

\begin{tabular}{ccccccccc}
\hline Vegetable & Parts & Chrysene & Fluoranthene & Fluorene & B(a)P & Acenaphthylene & Naphthalene & Anthracene \\
\hline Okra & Total & $\mathrm{Nd}$ & $3.79 \pm 0.11$ & $60.66 \pm 2.1$ & $\mathrm{Nd}$ & $5.80 \pm 0.03$ & $6.77 \pm 0.03$ & $2.09 \pm 0.01$ \\
Spinach & Total & $\mathrm{Nd}$ & $3.82 \pm 0.12$ & $52.84 \pm 1.9$ & $\mathrm{Nd}$ & $4.88 \pm 0.02$ & $6.89 \pm 0.03$ & $2.18 \pm 0.01$ \\
Cabbage & Total & $\mathrm{Nd}$ & $3.79 \pm 0.08$ & $28.39 \pm 1.1$ & $8.30 \pm 0.03$ & $2.02 \pm 0.01$ & $6.25 \pm 0.02$ & $2.05 \pm 0.01$ \\
Tomato & Total & $7.53 \pm 0.2$ & $3.78 \pm 0.09$ & $19.20 \pm 0.9$ & $5.11 \pm 0.02$ & $\mathrm{Nd}$ & $5.63 \pm 0.02$ \\
\end{tabular}

Table 3. Concentration of PAHs ( $\mu \mathrm{g} / \mathrm{kg}$ ) determined in core and peels of vegetables samples collected from (Sandoz road) near Jamshoro power plant.

\begin{tabular}{ccccccccc}
\hline Vegetable & Parts & Chrysene & Fluoranthene & Fluorene & B(a)P & Acenaphthylene & Naphthalene & Anthracene \\
\hline Bittergourd & Core & $\mathrm{Nd}$ & $\mathrm{Nd}$ & $86.01 \pm 2.5$ & $\mathrm{Nd}$ & $6.90 \pm 0.02$ & $5.71 \pm 0.02$ & $2.11 \pm 0.01$ \\
& $\mathrm{Peel}$ & $\mathrm{Nd}$ & $\mathrm{Nd}$ & $54.43 \pm 2$ & $\mathrm{Nd}$ & $3.20 \pm 0.04$ & $5.82 \pm 0.06$ & $2.07 \pm 0.02$ \\
Cucumber & Core & $6.17 \pm 0.02$ & $3.78 \pm 0.08$ & $47.46 \pm 1.4$ & $5.32 \pm 0.02$ & $0.94 \pm 0.01$ & $\mathrm{Nd}$ & $2.05 \pm 0.01$ \\
& Peel & $2.76 \pm 0.02$ & $\mathrm{Nd}$ & $26.33 \pm 1.3$ & $5.11 \pm 0.05$ & $23.54 \pm 0.8$ & $5.62 \pm 0.06$ \\
Eggplant & Core & $7.43 \pm 0.02$ & $\mathrm{Nd}$ & $87.34 \pm 2.4$ & $5.11 \pm 0.01$ & $6.01 \pm 0.02$ & $5.81 \pm 0.02$ & $2.14 \pm 0.01$ \\
& Peel & $\mathrm{Nd}$ & $\mathrm{Nd}$ & $66.40 \pm 2.4$ & $\mathrm{Nd}$ & $2.85 \pm 0.02$ & $5.61 \pm 0.06$ & $2.08 \pm 0.02$ \\
\hline
\end{tabular}

Table 4. Concentration of PAHs ( $\mu \mathrm{g} / \mathrm{kg}$ ) determined in vegetables samples collected from (Sandoz road) near Jamshoro power plant.

\begin{tabular}{|c|c|c|c|c|c|c|c|}
\hline Vegetable & Chrysene & Fluoranthene & Fluorene & $\mathbf{B}(\mathbf{a}) \mathbf{P}$ & Acenaphthylene & Naphthalene & Anthracene \\
\hline Spinach & $11.85 \pm 0.08$ & $3.80 \pm 0.04$ & $58.36 \pm 2.1$ & $5.14 \pm 0.03$ & $3.97 \pm 0.02$ & $5.76 \pm 0.04$ & $2.04 \pm 0.02$ \\
\hline Coriander & $\mathrm{Nd}$ & $\mathrm{Nd}$ & $57.90 \pm 2$ & $5.20 \pm 0.03$ & $2.86 \pm 0.02$ & $6.00 \pm 0.03$ & $2.37 \pm 0.02$ \\
\hline Tomato & $12.13 \pm 0.09$ & $3.78 \pm 0.04$ & $83.35 \pm 2.7$ & $5.14 \pm 0.03$ & $6.43 \pm 0.04$ & $5.68 \pm 0.03$ & $2.08 \pm 0.02$ \\
\hline
\end{tabular}


Table 5. Concentration of PAHs in $\mu \mathrm{g} / \mathrm{kg}$ in cores and peel of vegetables samples collected from cultivated area of Latifabad Hyderabad.

\begin{tabular}{|c|c|c|c|c|c|c|c|c|}
\hline Vegetable & Parts & Chrysene & Fluoranthene & Fluorene & $\mathbf{B}(\mathbf{a}) \mathbf{P}$ & Acenaphthylene & Naphthalene & Anthracene \\
\hline \multirow[t]{2}{*}{ Cucumber } & Core & $6.20 \pm 0.04$ & $\mathrm{Nd}$ & $43.18 \pm 1.5$ & $5.14 \pm 0.03$ & $0.58 \pm 0.01$ & $\mathrm{Nd}$ & $2.02 \pm 0.02$ \\
\hline & Peel & $\mathrm{Nd}$ & $\mathrm{Nd}$ & $34.81 \pm 0.91$ & $5.12 \pm 0.03$ & $10.02 \pm 0.2$ & $\mathrm{Nd}$ & $2.03 \pm 0.02$ \\
\hline \multirow[t]{2}{*}{ Beet } & Core & $4.80 \pm 0.02$ & $3.78 \pm 0.04$ & $198.35 \pm 4$ & $\mathrm{Nd}$ & $9.01 \pm 0.08$ & $8.11 \pm 0.07$ & $2.15 \pm 0.02$ \\
\hline & Peel & $\mathrm{Nd}$ & $4.05 \pm 0.02$ & $561.98 \pm 5$ & $\mathrm{Nd}$ & $29.52 \pm 0.3$ & $11.59 \pm 0.2$ & $2.73 \pm 0.02$ \\
\hline \multirow[t]{2}{*}{ Eggplant } & Core & $\mathrm{Nd}$ & $3.80 \pm 0.04$ & $379.64 \pm 5$ & $\mathrm{Nd}$ & $18.70 \pm 0.7$ & $8.72 \pm 0.07$ & $2.22 \pm 0.02$ \\
\hline & Peel & $\mathrm{Nd}$ & $3.80 \pm 0.02$ & $132.41 \pm 4$ & $\mathrm{Nd}$ & $20.99 \pm 0.2$ & $7.95 \pm 0.12$ & $2.27 \pm 0.02$ \\
\hline
\end{tabular}

Table 6. Concentration of PAHs in $\mu \mathrm{g} / \mathrm{kg}$ in vegetables samples totally analyzed collected from cultivated area of Latifabad Hyderabad.

\begin{tabular}{lccccccr}
\hline \multicolumn{1}{c}{ Vegetable } & Chrysene & Fluoranthene & Fluorene & B(a)P & Acenaphthylene & Naphthalene & Anthracene \\
\hline Coriander & $\mathrm{Nd}$ & $3.78 \pm 0.03$ & $264.84 \pm 2.1$ & $\mathrm{Nd}$ & $\mathrm{Nd}$ & $6.67 \pm 0.06$ & $2.35 \pm 0.02$ \\
Okra & $\mathrm{Nd}$ & $3.84 \pm 0.03$ & $412.86 \pm 4.3$ & $\mathrm{Nd}$ & $19.47 \pm 0.22$ & $9.17 \pm 0.1$ \\
Spinach & $\mathrm{Nd}$ & $3.80 \pm 0.03$ & $281.01 \pm 2.4$ & $\mathrm{Nd}$ & $13.39 \pm 0.14$ & $\mathrm{Nd}$ & $2.15 \pm 0.02$ \\
Tomato & $1.50 \pm 0.02$ & $\mathrm{Nd}$ & $208.20 \pm 1.95$ & $5.40 \pm 0.05$ & $9.75 \pm 0.12$ & $7.69 \pm 0.07$ & $2.06 \pm 0.02$ \\
\hline
\end{tabular}

\section{Conclusion}

The results showed that all the vegetables were contaminated with varying range of PAHs. The samples collected from industrial areas contained larger concentration of PAHs compared with samples collected from the market because smoke coming from industries in large quantity deposits to crops located to that area. Highmolecular-weight PAHs had higher concentrations relative to PAHs with low molecular weights. In most of the vegetables, all the peels were found to be more contaminated than cores.

\section{References}

1. N. S. Liland, A. C. Simonsen, A. C. Duelund, L. Torstensen, B. E. Berntssen, M. H. Mouritsen, O. G., Chem. Phys. Lpids, 184 (2014) 18.

https://doi.org/10.1016/j.chemphyslip.2014.0 $\underline{8.004}$

2. G. R. Liu, X. Peng, R. K. Wang, Y. Z. Tian, G. L. Shi, J. H. Wu, P. Zhang, L. D. Zhou, and Y. C. Feng, J. Hazard. Mat., 283 (2015) 462.

https://doi.org/10.1016/j.jhazmat.2014.09.062
3. S. Otto, T. Streibel, S. Erdmann, S. Klingbeil, D. Schulz-Bull, and R. Zimmermann, Mar. pollut. Bull., 99 (2015) 35.

https://doi.org/10.1016/j.marpolbul.2015.08. $\underline{001}$

4. X. Duan, J. Liu, D. Zhang, P. Yin, Y. Li and X. Li., Mar. Pollut. Bull., 97 (2015) 309. https://doi.org/10.1016/j.marpolbul.2015.05. 071

5. Y. Yu, Q. Li, H. wang, B. wang, X. wang, A. Ren and S. Tao, Environ. Pollut., 205 (2015) 70.

https://doi.org/10.1016/j.envpol.2015.05.022

6. N. L. Devi, I. C. Yadav, Q. Shihua, Y. Dan, G. Zhang and P. Raha, Chemosphere, 144 (2016) 493.

https://doi.org/10.1016/j.chemosphere.2015.0 $\underline{8.062}$

7. X. Wang, P. Gong, J. Sheng, D. R. Joswiak and T. Yao, Atmos. Environ., 115 (2015) 124. https://doi.org/10.1016/j.atmosenv.2015.04.0 $\underline{50}$

8. G. L. Yuan, L. J. Wu, Y. Sun, J. Li, C. J and G. H. wang, Environ. Pollut., 203 (2015) 137. 
https://doi.org/10.1016/j.envpol.2015.04.002

9. H. Zhi, Z. Zhao and L. Zhang, Chemosphere, 119 (2015) 1134.

https://doi.org/10.1016/j.chemosphere.2014.0 9.054

10. D. Jiang, C. Xin, W. Li, J. Chen, F. Li, Z. Chu, P. Xiao and L. Shao, Food Chem. Toxicol., 83 (2015) 61.

https://doi.org/10.1016/j.fct.2015.06.001

11. M. A. Alghamdi, M. S. Alam, J. Yin, C. Stark, E. Jang, R. M. Harrison, M. shamy, M.

I. Khodar and I. I. Shabbaj, Sci. Total Environ., 506 (2015) 401. https://doi.org/10.1016/j.scitotenv.2014.10.0 $\underline{56}$

12. O. Gul, M. Dervisoglu, M. Mortas, O. Aydemir, E. Ilhan and K. Aksehir, J. Food Compos. Anal., 37 (2015) 82.

https://doi.org/10.1016/j.jfca.2014.07.004

13. E. C. Teixeira, D. M. Agudelo-Castañeda and C. D. P. Mattiuzi, Sci. Total Environ., 538 (2015) 212.

https://doi.org/10.1016/j.scitotenv.2015.07.0 $\underline{72}$

14. C. Yap, S. Gan and H. Ng, J. Hazard. Mater., 177 (2010) 28.

https://doi.org/10.1016/j.jhazmat.2009.11.07 $\underline{8}$

15. J. L. Domingo and M. Nadal, Food Chem. Toxicol., 86 (2015) 144.

https://doi.org/10.1016/j.fct.2015.10.002
16. K. Dost and C. İdeli, Food Chem., 133 (2012) 193.

https://doi.org/10.1016/j.foodchem.2012.01.0 $\underline{01}$

17. G. Li, S. Wu, L. Wang and C. C. Akoh, Food Control, 59 (2016) 328.

https://doi.org/10.1016/j.foodcont.2015.06.0 $\underline{03}$

18. A. Aragón, R. M. Toledano, A. Vázquez, J. Villén and J. M. Cortés, Talanta, 139 (2015) 1.

https://doi.org/10.1016/j.talanta.2015.02.028

19. H. Zhi, Z. Zhao and L. Zhang, Chemosphere, 119 (2015) 1134.

https://doi.org/10.1016/j.chemosphere.2014.0 9.054

20. M. W. Ashraf, S. I. H. Taqvi, A. R. Solangi and U. A. Qureshi, J. Chem., 2013 (2012). http://dx.doi.org/10.1155/2013/873959

21. A. Abou-Arab, M. Abou-Donia, F. El-Dars, O. Ali and H. A. Goda. Int. J. Curr. Microbioll. Appl. Sci., 3 (2014) 277. https://www.researchgate.net/profile/Farida El-Dars2/publication/308787421.

22. Muhammad Waqar Ashraf \& A. Salam, Bull Environ. Contam. Toxicol., 88 (2012) 543. doi: $10.1007 / \mathrm{s} 00128-012-0528-8$ 